\title{
ADAPTIVE REUSE HERITAGE BUILDINGS ADDRESSING SUSTAINABILITY POTENTIALS: ANALYTICAL CASE STUDIES IN SHARJAH, UNITED ARAB EMIRATES
}

\author{
IMAN IBRAHIM \& FATMA ELTARABISHI \\ University of Sharjah, UAE
}

\begin{abstract}
Due to the rapid growth and development worldwide, nations tend to preserve their historic sites that represent their heritage. The adaptive reuse strategy is used to help communities maintain their own local identity and culture. The adaptive reuse terminology is used interchangeably with terms such as renovation, refurbishment and rehabilitation. However, this study will distinguish each term based on a framework discussed in the literature. The research aims to determine the additional value added when the potentials of three pillars of sustainability are considered in the adaptive reuse heritage buildings. Two case studies, namely The Chedi Al Bait hotel and the Sharjah Art Foundation (SAF) in Sharjah, United Arab Emirates (UAE), are selected on the basis of their historical significance and unfitness. The sustainability potentials inherited in each case will be assessed and analyzed. Based on the analytical studies, it is concluded that the local government in the UAE as decision makers have successfully achieved the added value of sustainability enhancing the adaptive reuse of the two case studies discussed.
\end{abstract}

Keywords: adaptive reuse, sustainability value, Al-Bait Hotel, Sharjah Art Foundation (SAF).

\section{INTRODUCTION}

Heritage buildings are considered as an integral part of a nation's identity, tradition and culture. It is crucial to preserve such buildings in order to maintain local identity and culture. Unfortunately, governments tend to be absent-minded and fail to invest in them to have a fruitful source of outcome for the country. For example, the Antoniadis Palace in Alexandria, Egypt was deteriorated due to lack of maintenance and repair [1]. In fact, the biggest threat governments pose to heritage and ancient buildings is in deciding to demolish them. The obsolescence of heritage buildings is economically unsustainable [2] and contrary to achieving sustainability goals generally [3]. One of the most implemented ways to ensure the maintaining of historic buildings is to adapt them to modern use.

Adaptive reuse refers to the process of reconstructing an existing building for a different purpose other than the original purpose that was built for [4]. This process is applied in different facilities such as museums, mosques, residential buildings and offices [5]. Adaption of existing old buildings results in many tangible and intangible benefits to the public and government and also in terms of environmental sustainability, through the reuse of existing buildings and increasing the building's life expectancy. Adaptive reuse is an eco-friendly solution to built environment needs through reducing material, transport and energy consumption and lowering pollution associated with new building projects [3]. Developers can save cost and time when investing in the reconstruction of old buildings rather than new construction projects [4]. Accordingly, reconstruction sites expose neighbours to less noise pollution compared to typical construction sites. Zulkifli advocated that demolition cost is as high as to reach $10 \%$ of the total cost of new project construction [4]. One important intangible benefit is that younger generations will be able to visualize and respect their history and connect with their past, heritage and locality [6]. Bringing life back to dumbed buildings 
create jobs for locals where rehabilitation and restoration skills are required. Although reconstruction prevents depopulation of urban areas in a country [2], eventually it may result in a high urban density [7].

Adaptive reuse is a complex process which similar materials and construction method should be used. In Australia, architects, developers and building managers were interviewed by Bullen and Love [8] where results revealed about $85 \%$ of participants stated that the viability of recycling existing materials is one of the critical barriers to implement the adaptive reuse. Because buildings are old and neglected, workers may have to strictly follow safety and health requirements. The assessment of an old building's plan and its operation is a time-consuming exercise [7].

Adaptive reuse projects can be described by a wide range of terminologies such as retrofitting, refurbishment, rehabilitation. The wide diversity of terminologies is due to the type and scale of building, existing conditions and the construction activities conducted during these projects. In other words, authors in literature used the terminologies based on the status of the building and what is necessarily needed for reconstruction. No standards to select a terminology for each project, each case was dealt with differently. Authors have justified their terminology selection based on their own perceptions and reviewed literature. For example, Ebbert [9] used the term refurbishment to indicate the replacements of office facades and Ishak et al. [10] used refurbishment to accommodate modern building services and energy saving techniques. However, Bhuiyan et al. [11] have used refurbishment and rehabilitation interchangeably as the reviewed literature showed. Therefore, in order to set minds out, this study used the proposed framework by Shahi et al. [2] which illustrates the clear definition of each terminology based on the literature reviewed. The study has eliminated the terminologies "revitalization" and "modernization" due to their less common use in the literature. Fig. 1 summarizes the most common terminologies based on Shahi's literature review.

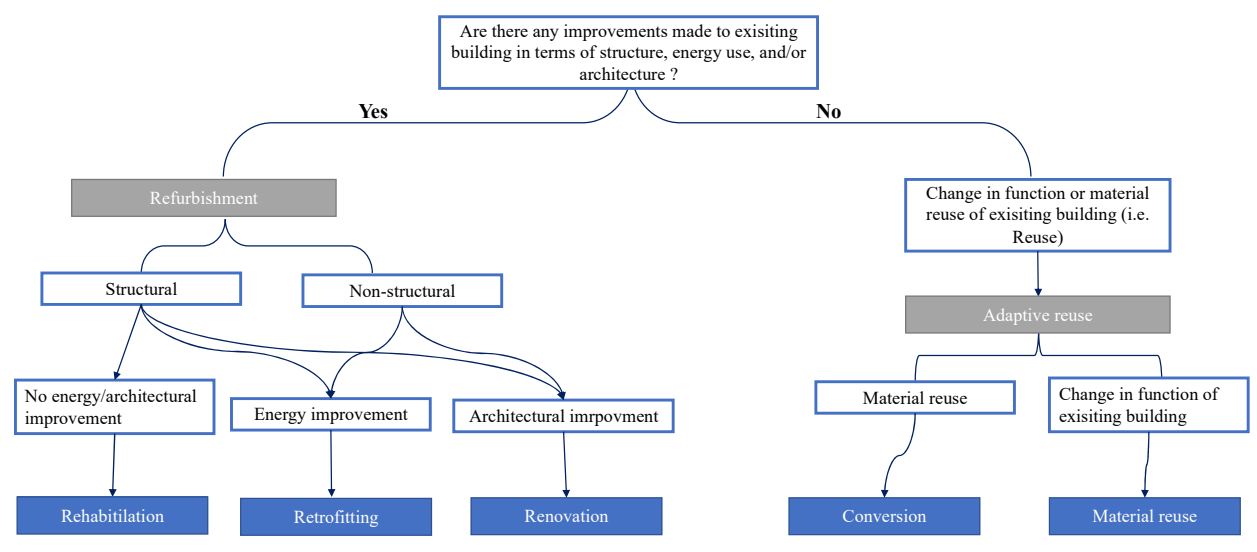

Figure 1: Refurbishment and adaptive reuse definitions framework. (Source: Authors.)

The authors categorized the adaptation of buildings to two categories: Refurbishment and Adaptive use. The term refurbishment is considered as an umbrella to retrofitting, renovation and rehabilitation. Simply, applying any additional structural or non-structural improvements to an existing building falls under the term "Refurbishment." Besides, any changes to the structural plan of a building falls under the adaptive reuse category. The adaptive reuse term 
also includes removal or change in a building's materials. Using the discussed framework, this study will identify which terms best describe the following two case studies in the United Arab Emirate: The Chedi Al Bait hotel and the Sharjah Art Foundation (SAF) in Sharjah.

\section{ADAPTIVE REUSE VALUE}

In this modern world, the adaptation of old buildings has increased in trend. Misirlisoy and Günçe [6] believe that adaptive reuse calls for architectural conservation which ensures the significance of economic, social and cultural sustainability to the urban communities. Similarly, Elsorady [12] states that heritage buildings are heritage symbols that should be preserved to retain a country's identity.

Adaptive reuse can transform heritage buildings to accessible and useful places as well as to benefit the area in a sustainable manner. The adaptive reuse of buildings in the Old City of Bethlehem in Palestine and Visby old city in Sweden are two cases that presented their positive contribution to build a sustainable environment [3]. In terms of social sustainability, a stronger connection between past and future generations have been created. For economic sustainability, more jobs are offered, and tourists are attracted to the cities. Regarding the environmental sustainability, embodied energy (i.e., energy consumed from the acquisition of natural resources to product delivery) was reduced.

Adaptive reuse is a complex process where decision makers have to consider many aspects in order to obtain a well-developed heritage building that follows the modern community. This is discussed in the study conducted by Misırlısoy and Günçe [6]. They designed a holistic model for developing adaptive reuse strategies for heritage buildings. The model illustrates five steps that should be holistically considered to reach a decision of the new use for the heritage buildings. One of the important steps in the model is to analyse the existing condition of a building such as its physical character and heritage values. Following strategies and analysing the heritage building is crucial in order to make successful decisions. Several adaptive reuse projects reported various problems for example cracks in masonry walls and concrete slabs, roof erosion and roof leakage and effective solutions were given [13]. Sandbhor and Botre [14] highlight the importance of evaluating the building's structure as it provides a valuable source of knowledge regarding their weaknesses and the ways they respond to extreme conditions.

Correspondingly, Reiner [15] set out 13 elements that should be considered in heritage buildings for an outstanding adaptive reuse. Bin Zulkifli [4] used these elements to evaluate three case studies in three different countries namely the UK, Sarawak and Denmark. Elsorady [12] has identified her own indicators including physical characteristics, building function, public perception which were produced from the literature to evaluate the Alexandria National Museum in Egypt. The results showed that most of the indicators were achieved and sustained. However, Günçe and Misırlısoy [16] assessed the success of adaptive reuse of buildings based on one factor: users experience. This shows that no standards are set to measure or determine the success of the adaptive reuse practices. The aim of this paper is to determine the sustainability potentials added value for heritage buildings adaptive reuse in Sharjah showing two different case studies with unique successful practice.

\section{CASE STUDIES IN SHARJAH, UNITED ARAB EMIRATES}

Sharjah is one of the seven emirates of the United Arab Emirates (UAE) and is considered the culture capital of the UAE. Sharjah enjoys a very rich heritage culture to date and it is well known for its strong commitment to art, culture and history [17] as Fig. 2 shows the old urban fabric of Sharjah. Most tourist places in Sharjah to visit are heritage and cultural. The emirate is also well-known for its dry climate. Constant efforts are made by the UAE 
government to preserve the historical identity of the UAE. The modern architecture in the UAE seems to hold the same values as the traditional architecture. This can be visualized through several project in the UAE such as the Abu Dhabi central market, Sharjah Central Souq, Al Bahr Towers. However, this paper will focus on the Al bait hotel and SAF in Sharjah briefing the history, design and building structure and nature of materials used.

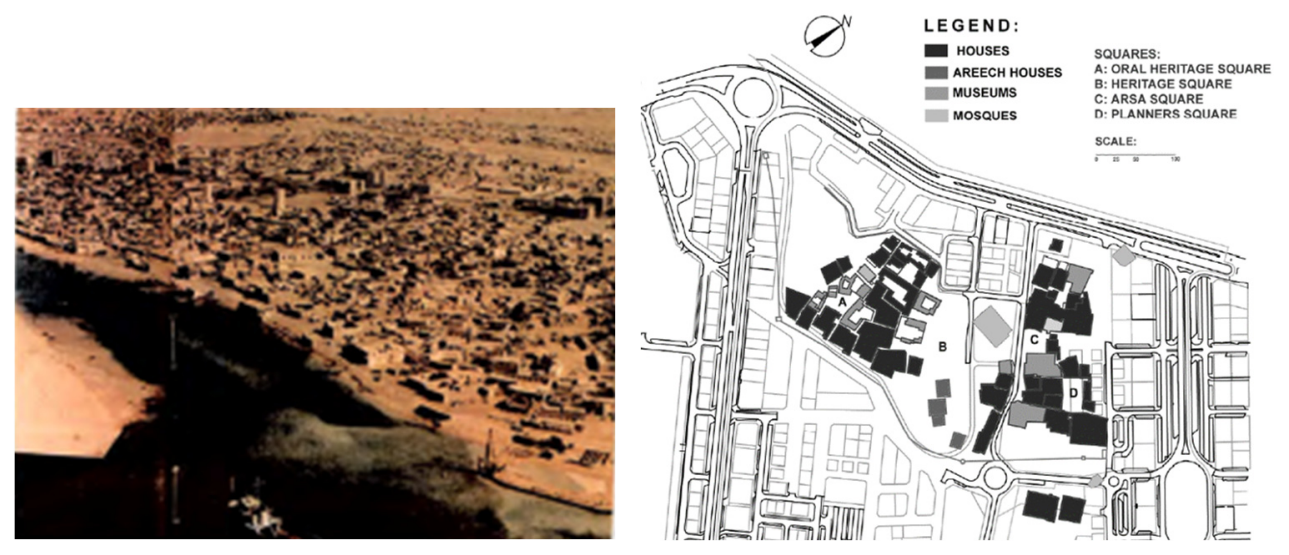

Figure 2: Heart of Sharjah Urban Fabric, with focus on Al Mirija historic area [18].
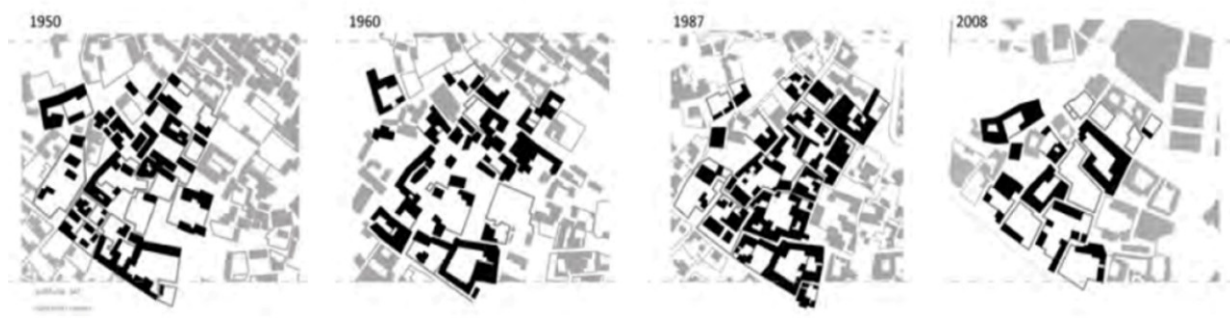

Figure 3: Sharjah urban fabric heritage area historic changes [17].

Sharjah's local architecture is a mix between the past and present. It is the place where old mid-rise and new high-rise constructions are observed in the same area [17] as shown in Fig. 3. Most of the old buildings are 50 years old and were built of coral stone walls and palm tree roofs [19]. The Marija area is a unique zone that accommodates all the old surviving constructions; located in the center of Sharjah city. In fact, it is the most historically and architecturally significant area in Sharjah city. In the late 19th, the Marija area construction situation suffered badly and as a result, the conservation process in Sharjah started with that area. Sharjah government recommended to preserve three buildings in the Marija area: AlMidfa House, Al-Naboodah House and the Al-Mugsuba Tower due to their uniqueness and architectural significance. Indeed, the buildings were restored and conserved starting with Al-Naboodah House [18]. The success of these projects has motivated owners to handle other reconstruction and replication projects. Therefore, the area become an attraction spot for heritage tourism. In 1998, Sharjah's rulers decided not only to restore old buildings, but to replicate and rebuild as the Sharjah Art Foundation case. All the buildings were given a 
contemporary touch while maintaining the traditional architecture with the aim of increasing the cultural and social activities in the region. This paper will mainly focus on the Al bait hotel and SAF cases due to their high economic and social values. The aim is to determine the sustainability values of the heritage adaptive reuse for the buildings from different aspects; social, environmental and economic.

\subsection{Sharjah Art Foundation (SAF)}

The Sharjah Art foundation (SAF) is the producer and leader of contemporary art within the Emirate of Sharjah and the Middle East region. The foundation consists of a series of existing old historic buildings and five new buildings to match the old series. It has accessible areas and various facilities such as cafes, gallery spaces, and courtyards for concerts. This project took three years and in 2013, doors were open for visitors. It is close to the intersection between Al Merija Street and Corniche Street as well as near to Al Zahra mosque (Fig. 4). The SAF is a legal public body funded by the government and is a non-profit international organization [20]. The foundation's commitment is to sustain Sharjah's heritage through exhibitions, performances and programs in Sharjah and across the UAE that are mainly hosted in historical buildings that are now reused as educational centres. One of the core events is the Sharjah Biennial; a global event where contemporary artists attend and participate from around the world.

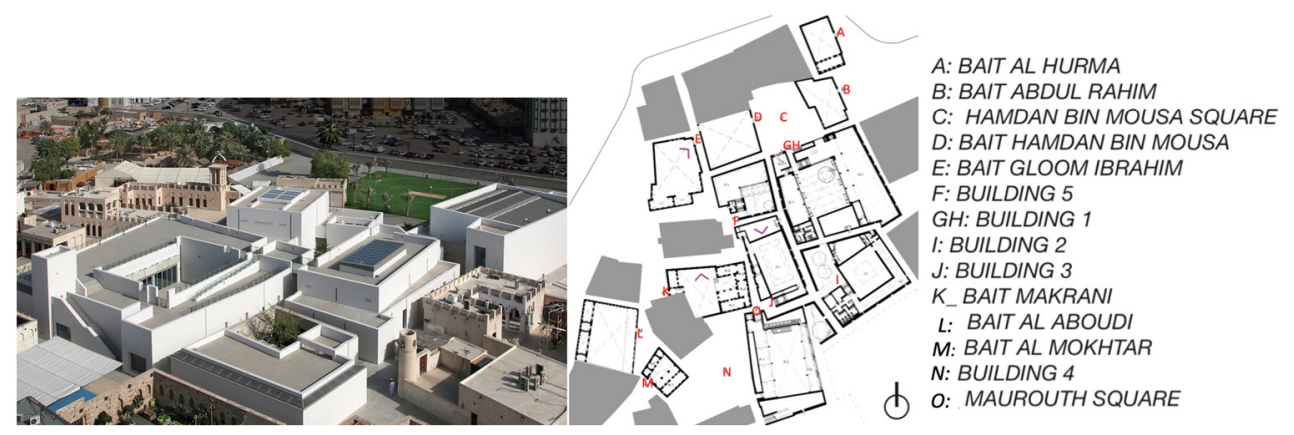

Figure 4: Sharjah Art Foundation (SAF) ground floor plan and space functions [17].

As the Sharjah Biennial event started to attract attention, more spaces were needed to facilitate the installations and display of contemporary art. Therefore, five new buildings were needed to fit in the heritage area and to match the old heritage buildings. The whitecube-like buildings (Fig. 4) followed the street or circulation pattern that must have existed back in time. Each building's scale varies where larger buildings are built at the center and shorter ones are at the edges of the foundation. They are designed simply with no curves or sloping planes. All building used concrete structure except one that used steel structure. Concrete pavements, white plastered/painted walls and clear insulated glass are the materials used throughout the project.

\subsubsection{Environmental sustainability value}

The value to the environment is a crucial part of heritage as it can significantly affect the visitors experience and it improves attractiveness to the heritage-reused place. The environmental value is closely associated with the natural landscape and green spaces. In the 
year 2020, Tu [21] study stated the environmental value as the most important factor when assessing heritage buildings for adaptive reuse feasibility.

Back in the old days, courtyards were an important feature in all houses. The SAF have designed the new five buildings to be surrounded by courtyards, as shown in Fig. 5. Such outdoor spaces create natural ventilation and as a result, visitors can smell a clean air breeze. Similarly, the narrow circulations between the modern and heritage buildings are designed to create shaded areas. In fact, the shaded areas act as a cooling technique for the pedestrians due to the hot and dry weather in Sharjah.

Plants, greenspaces, parks and gardens are important natural elements to give life to the heritage site. However, most of the SAF is paved, with little landscape. Thus, a low chance of plants could survive due to the dry-humid weather in the UAE. Close to the entrance of the foundation, a parking lot has been transformed to a landscaped pedestrian space to create a welcoming space for visitors. One of the courtyards have relatively denser trees than other courtyards since it may be exposed to a better weather condition. Lighting is another factor that has been taken care of as windows were adjusted using blinds and applying films to achieve the desired levels of natural light.

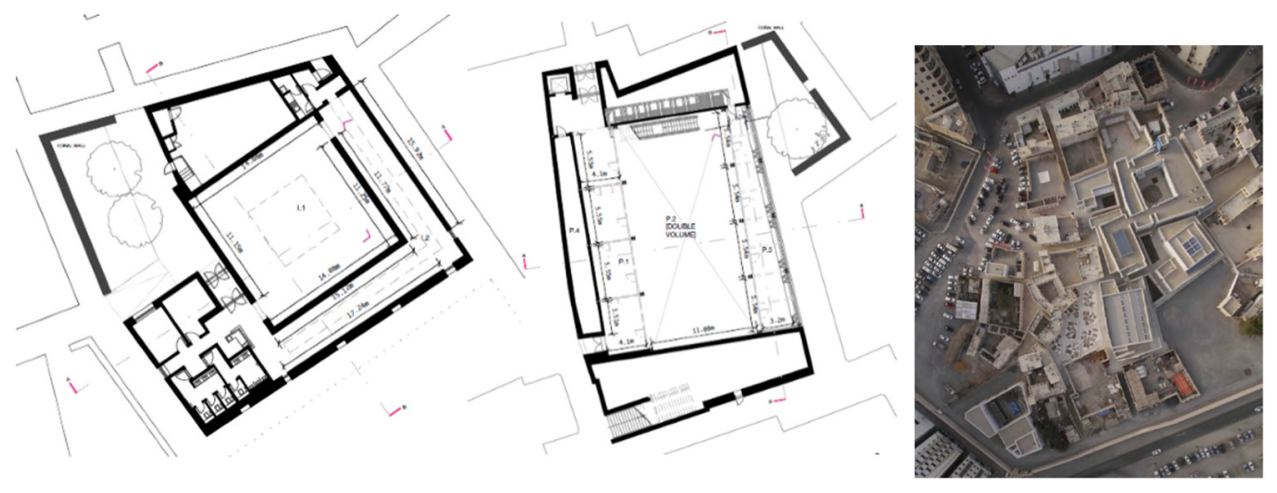

Figure 5: SAF exhibition buildings ground floor plans showing the harmony with the heritage urban fabric [17].

The traditional compact urban fabric is used in the very narrow spaces to provide shaded aisles for pedestrians. Also, the irregular geometry of streets allows wind circulation bringing cool breezes (Fig. 6).
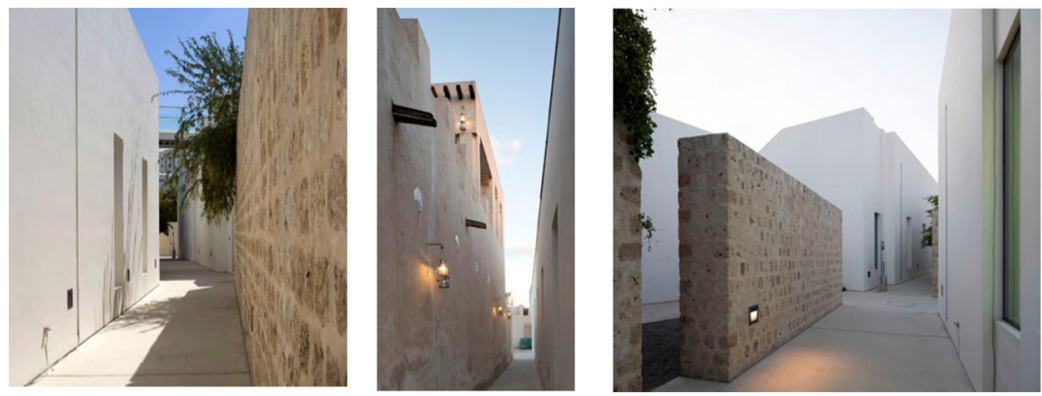

Figure 6: SAF narrow streets and irregular spaces allowing wind circulation [17]. 


\subsubsection{Economic sustainability value}

Several adaptive reuse projects have failed since they do not meet the requirements and needs of the neighbourhood and consequently, no income was generated. A high economic efficiency is only achieved when economic and non-economic aspects (including environmental and social aspects) are considered [21]. Indeed, SAF has attracted visitors locally and globally which is economically beneficial, positively affecting the city's economic development. The SAF project won the Aga Khan award for architecture in 2019. This has definitely served the local government economic situation. Accordingly, investors and developers were interested to be involved in adaptive reuse projects.

The architects and developers tried to maximize the efficiency of the material used, preserving $40 \%$ of the urban fabric. The standard construction methods were used for all the new buildings. The project relied on local labour and no specialized labour. To make the foundation accessible, air conditioning system, mechanical, electrical and plumbing equipment were installed. Also, the UAE's first nitrogen-based fire-suppression system was installed. Despite the fact that such systems may be expensive, but they serve the visitor's safety and enjoyment.
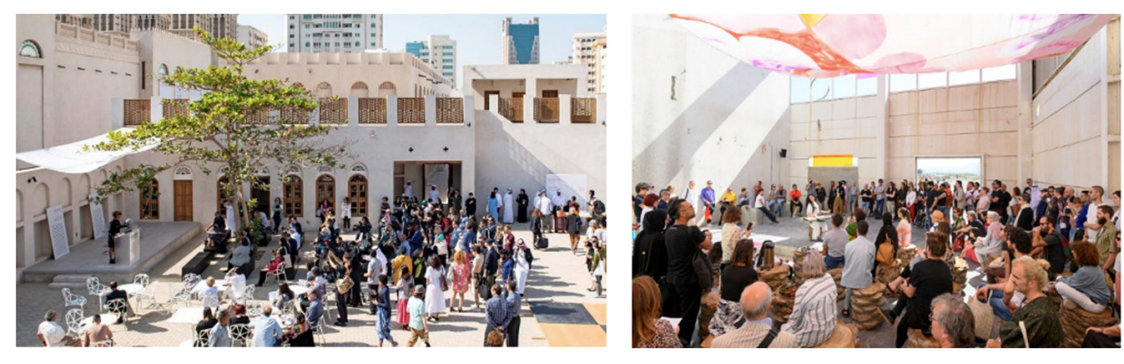

Figure 7: Sharjah Art Biennial, the International hub for artists [17].

\subsubsection{Social sustainability value}

The adaptive heritage reuse raises the social values the most. A harmonic relationship occurs between visitors and the environmental features discussed earlier. Courtyards allow social gatherings and meetings as well as to provide some stress relief and tranquillity for visitors. The natural landscape and green spaces evoke tranquillity and an interesting experience to talk about to friends. Bull and Al-Thani [22] concluded that leisure time for gulf countries nationals involves the family gatherings and rarely going to cultural institutions. Therefore, courtyards, cafes and green spaces are facilities that will bring in positive social responses to the project. In fact, the combination of displaying the modern art with the restoration of the cultural heritage as well as the different social activities afforded has built a relationship with national, resident and non-resident visitors from different ages. This relationship helps SAF increases visitors' knowledge about art and artists within the community, thus attracting more visitors to exhibitions and their other programs.

The cultural value is not to be overlooked. Visitors are exposed to an interesting experience as well widening their knowledge. The heritage site shapes the cultural value. For example, stone coral, a traditional building material for walls is used in the circulation areas and appears like masonry walls. The combination of the modern and traditional material will bring the attention of the occupants and give them the opportunity to visualize the history of the city. For international visitors, they will have the chance to know the history of the community and feel the sense of belonging. 

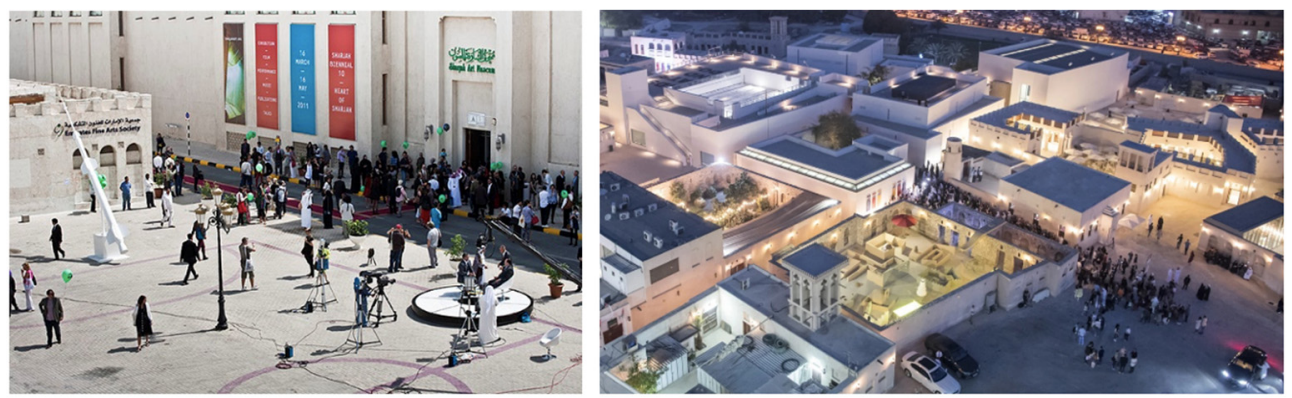

Figure 8: Art exhibitions encouraging local and international community to be introduced to local heritage [17].

\subsection{The Chedi Al Bait hotel}

The Chedi Al Bait Sharjah hotel is a five-star hotel that is located in the heart of Sharjah. The term 'Al Bait' is referred to as 'the home' which is considered as a unique place that brings the UAE history back to life. The luxury hotel is $10,000 \mathrm{~m}^{2}$ with 53 room resorts that is managed by General Hotel Management (GHM) in partnership with the Sharjah Investment and Development Authority (Shurooq). It is located in Sharjah (20 minutes ride from the city of Dubai) adjacent to Corniche Road running along Sharjah Creek and Al Hisn Street. The hotel features events and business facilities where resorts or private rooms are booked for events [23].
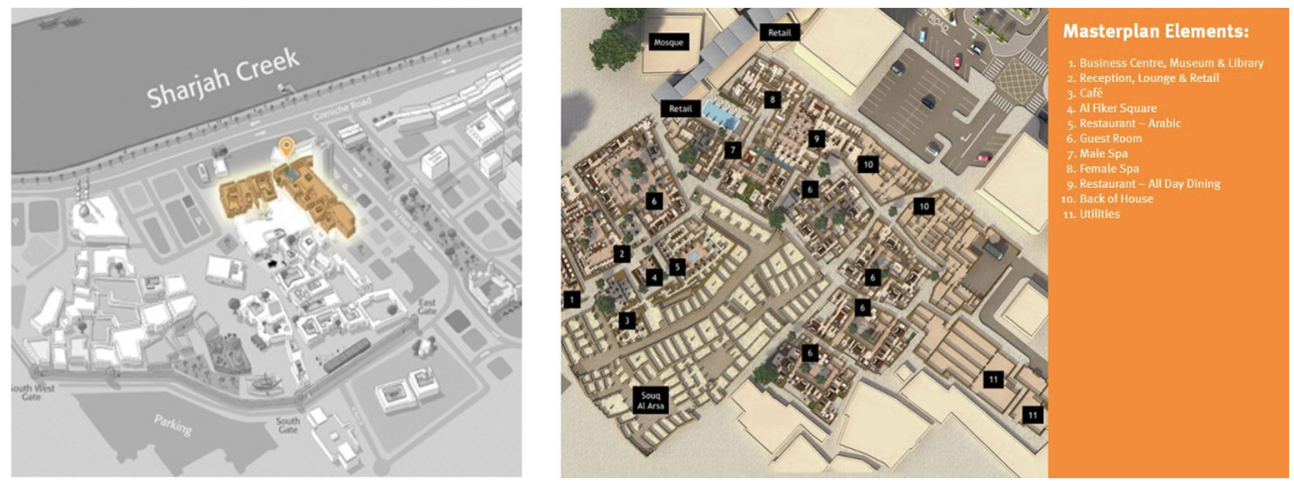

Figure 9: Al Bait Hotel master plan complex of old heritage buildings [24].

The preservation of the hotel is one of the region's biggest restoration projects that has not ended yet and is expected to end by 2025 . However, the hotel was opened and available for booking in 2018. Al Bait Sharjah guests experience the traditional souks in the area, including Souk Al Shanasiyah, one of the most ancient markets in the Gulf region [25]. Guests are tasting the history of UAE mixed with the modern touch. 

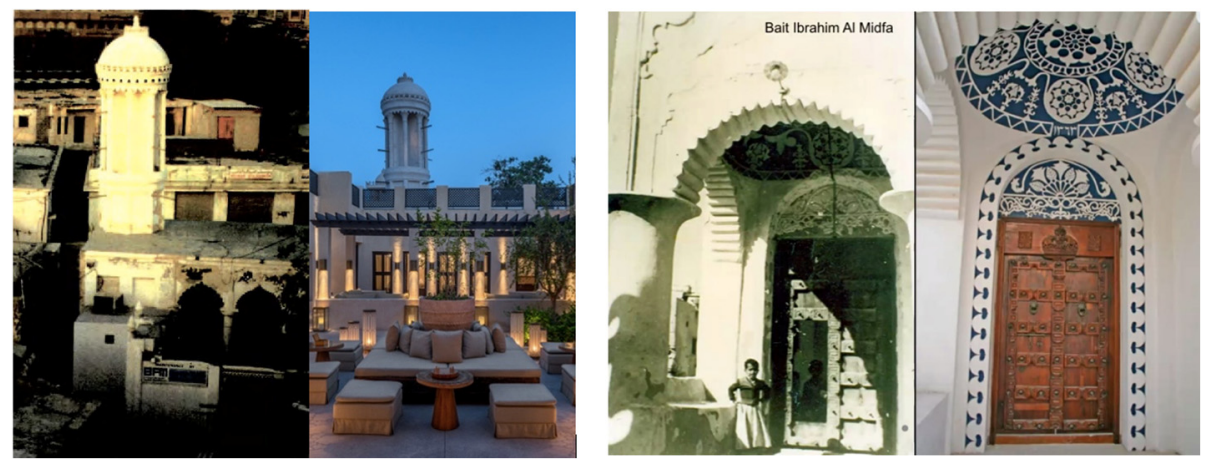

Figure 10: Unique architectural elements showing the original building before and after the adaptive reuse [18], [23].

Previously, Al bait was named as "Al-Midfa house" based on Al-Midfa family who are considered as one of the major merchant families in Sharjah. Back then in the early 1920s, it was designed and used as the main 'majlis' or meeting room for the men of the Al-Midfa family and as a rest house [18]. Mangrove poles supported the roof and mats of palm leaves were used as insulators. In the summer, Al-Midfa family would sleep in the courtyards under trees for a better quality sleep [18]. Unfortunately, it was neglected for many years and as a result saline erosion has occurred except in two elements: the wind tower and a fortified residential structure, as shown in Fig. 12. The rounded barjeel, or wind tower was a unique symbol of UAE's culture that was used as a natural ventilation during summer seasons. In 2012, Dr. Sheikh Sultan Bin Mohammad Al Qasimi announced the initiative of reviving the UAE's heritage and in 2013, the restoration of the Al-Bait hotel was started [26].
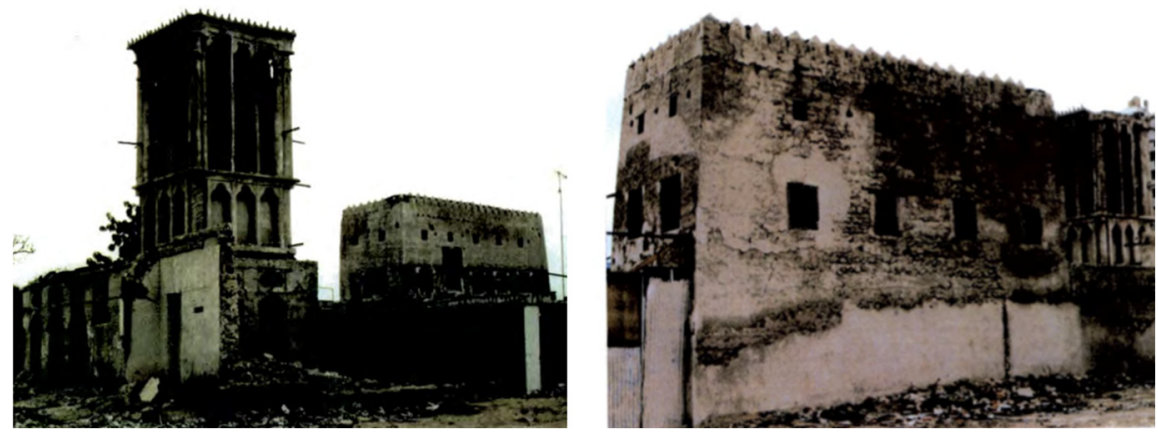

Figure 11: The original traditional house "Al Midfa house" before the adaptive reuse [18].

\subsubsection{Environmental sustainability value}

To significantly impact the visitors experience, Al bait hotel developers have restored several features. A significant architectural development to the courtyards is observed in Fig. 13. Trees are also planted to decorate the courtyard and allow visitors to enjoy the experience. Also, the round wind tower, a traditional method of ventilation, is conserved and guests visit the café to discover the wind tower. Natural lightning is ensured to occur in the rooms of the hotel during the day. 


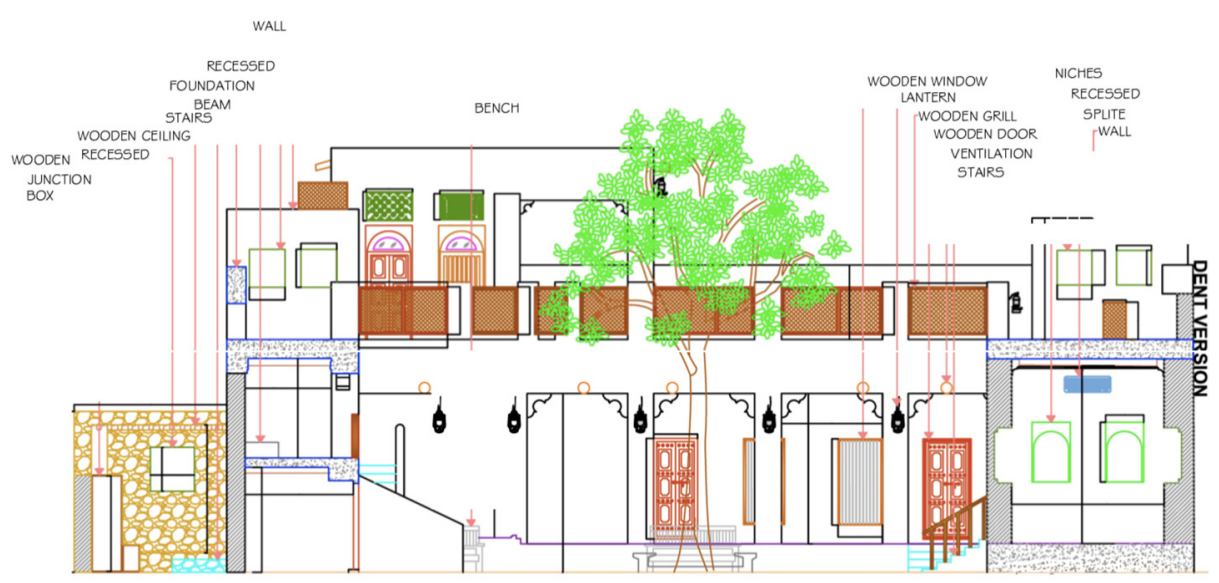

Figure 12: Cross section drawing showing the central courtyard space [27].

\subsubsection{Economic sustainability value}

The main aim of $\mathrm{Al}$ bait hotel is to have a unique tourism icon and to draw the attention of tourists and residents. Indeed, this is the case of Al Bait hotel. Economically, the developers of the project have used local materials such as traditional clay flooring, masculine leather and timber ceilings, shutters and doors. They have also selected traditional Emirati fabrics, patterns and ornaments [28]. This contribution increases the local market economy and local employment.
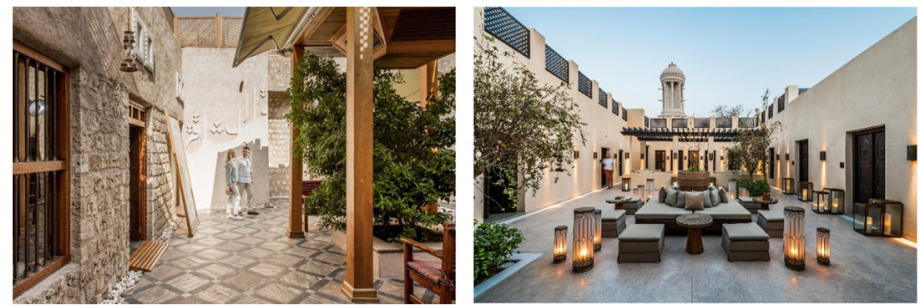

Figure 13: Interior views for Al Bait hotel showing the traditional treatment in luxury hotel [23].

Based on the visitors reviews, a travel agency for booking hotels, tourists come from everywhere in the world, including France, Germany, Saudi Arabia, United Kingdom, etc. The variety of nationalities and the good reviews for the hotel allow visitors to convey the cultural heritage to others, which improves the economic development of the city.

\subsubsection{Social sustainability values}

Based on many touristic booking sites, it is noticed Al Bait hotel is exceptionally rated 9.6 out of 10. All reviews reported by visitors were delightful, satisfied and enjoyed a comfortable tranquil stay in a busy city. The library facility available in the hotel has given a chance to the guests to induce knowledge about the history of the heritage site and know 
more about the history of the UAE. Gathering places in Al Bait hotel were important for guests to communicate with the heritage traditional touch.

Al Bait hotel experience is not limited for tourists from different nationalities, but also it gave locals the curiosity to go through a unique experience of their ancient's traditional architecture and the local social life, habits and traditions that the owner represented in the UAE government were very keen to present along with the luxurious services.

\section{CONCLUSION}

One of the aims of the paper is to identify the terminologies that best describes the two case studies discussed earlier. Fig. 1 is used to identify the SAF and Al Bait hotel terminologies. Regarding Al Bait hotel, it includes material reuse, change in function of existing building, architectural and structural improvements. Therefore, several terminologies can be used to describe Al bait hotel experience, such as adaptive reuse: conversion or material reuse, or refurbishment: retrofitting or renovation. For the SAF case, it includes material reuse, no change in function of existing building, architectural and structural improvements. It can be described as adaptive reuse: material reuse, or refurbishment: retrofitting or renovation.

The discussion of the two case studies within assessing sustainability aspects potentials proved that adaptive reuse for the heritage building has clear sustainability potentials. When explored the environmental sustainability values going through the architecture heritage elements and treatments adopting passive design strategies and vernacular architecture elements to deal with the hot dry climate, using the courtyards and wind towers for natural ventilation and natural lighting, and the compact urban fabric that provide shaded spaces and narrow streets allow wind circulation. Along with the economic aspects, that encouraged UAE government to support such adaptive reuse projects, where SAF become one of the most international artists' hubs in the world, and the social sustainability potential was clear when spreading the Emirate culture worldwide through the international Sharjah Biennale or Al Bait hotel experience, that provide the community with a local experience.

\section{REFERENCES}

[1] Elsorady, D.A., Adaptive reuse decision making of a heritage building antoniadis palace, Egypt. International Journal of Architectural Heritage, pp. 658-677, 2018.

[2] Shahi, S., Esnaashary Esfahani, M., Bachmann, C. \& Haas, C., A definition framework for building adaptation projects. Sustainable Cities and Society, 63, 2020.

[3] Ijla, A. \& Broström, T., The sustainable viability of adaptive reuse of historic buildings: The experiences of two world heritage old cities; Bethlehem in Palestine and Visby in Sweden. International Invention Journal of Arts and Social Science, 2(4), pp. 52-66, 2015.

[4] Bin Zulkifli, M.A.A., Design Principles of Adaptive Reuse: Case Studies on Dockyard, University Teknologi Malaysia, 2019.

[5] Alpler, Z.B., Şahin, N.P. \& Dağlı, U.U., A critical discussion of industrial heritage buildings adaptive re-use as film spaces, case study: Industrial heritage buildings at Istanbul. Journal of Architectural Conservation, 26(3), pp. 215-234, 2020.

[6] Misırlısoy, D. \& Günçe, K., Adaptive reuse strategies for heritage buildings: A holistic approach. Sustainable Cities and Society, 26, pp. 91-98, 2016.

[7] Bullen, P. \& Love P., Factors influencing the adaptive re-use of buildings. Journal of Engineering, Design and Technology, 9(1), pp. 32-46, 2011.

[8] Bullen, P.A. \& Love, P.E.D., Adaptive reuse of heritage buildings: Sustaining an icon or eyesore. RICS Construction and Property Conference, pp. 1652-1662, 2011. 
[9] Ebbert, T., Refurbishment Strategies for the Technical Improvement of Office Facades, RWTH Aachen University of Technology, 2010.

[10] Ishak, N., Ibrahim, F.A. \& Azizan, M.A., Analysis of factors influencing building refurbishment project performance. E3S Web of Conferences, 34, 2018.

[11] Bhuiyan, N.W., Islam S. \& Jones K., An approach to sustainable refurbishment of existing building. 31st Annual ARCOM Conference, pp. 1093-1102, 2015.

[12] Elsorady, D.A., Assessment of the compatibility of new uses for heritage buildings: The example of Alexandria National Museum, Alexandria, Egypt. Journal of Cultural Heritage, 15(5), pp. 511-521, 2014. DOI: 10.1016/j.culher.2013.10.011.

[13] Subramaniam, S.R., A review on repair and rehabilitation of heritage buildings. International Research Journal of Engineering and Technology, 3(4), pp. 1330-1336, 2016.

[14] Sandbhor, S. \& Botre, R., A systematic approach towards restoration of heritage buildings - A case study. International Journal of Research in Engineering and Technology, 2(3), pp. 229-238, 2013.

[15] Reiner, L.E., How to Recycle Buildings, 1979.

[16] Günçe, K. \& Misırlısoy, D., Assessment of adaptive reuse practices through user experiences: Traditional houses in the Walled City of Nicosia. Sustainability, 11, p. 540, 2019.

[17] Dada, R.A., Aga Khan for architecture report: Al-Mureijah art spaces. Aga Khan, 2019. https://www.akdn.org/architecture/project/al-mureijah-art-spaces. Accessed on: 15 Feb. 2021.

[18] Anderson, G., The Urban Conservative Dilemma, Durham University: Sharjah, UAE, 1991.

[19] Hadjri, K. \& Boussaa, D., Architectural and urban heritage conservation in the United Arab Emirates. Open House International, 32(3), pp. 12-26, 2007.

[20] Universes in Universe, Al Mureijah Art Spaces. https://universes.art/en/artdestinations/sharjah/art-spaces/saf-art-spaces\#c65424. Accessed on: 25 Feb. 2021.

[21] $\mathrm{Tu}, \mathrm{H}$. , The attractiveness of adaptive heritage reuse: A theoretical framework. Sustainability, 12, 2020.

[22] Bull, J. \& Al-Thani, S.H., Six things we didn't know: Researching the needs of family audiences in Qatar, 2013.

[23] UAE, Ghmhotels, The Chedi Al Bait, Sharjah, 2020. https://www.ghmhotels.com/en/ the-chedi-al-bait-sharjah/.

[24] ProTenders, Al Bait Hotel Renovation, 2019. https://www.protenders.com/projects/albait-hotel-renovation. Accessed on: 24 Feb. 2021.

[25] Kumar, K., Al Bait Sharjah: Combining authentic Emirati heritage with modernity. The Arab Weekly, 2018. https://thearabweekly.com/al-bait-sharjah-combiningauthentic-emirati-heritage-modernity. Accessed on: 25 Feb. 2021.

[26] Waqas, M., Traditional 5-star hotel to open in the heart of Sharjah. Arabian Gazette, 2013. https://arabiangazette.com/traditional-5-star-hotel-to-open-in-the-heart-ofsharjah-20130316/. Accessed on: 25 Feb. 2021.

[27] Shurooq, The Chedi Al Bait, 2021. https://shurooq.gov.ae/project/the_chedi_albait/. Accessed on: 24 Feb. 2021.

[28] Abdel-Razzaq, J., Sharjah's Al Bait Hotel creates an old village experience. Architectural Digest, 2019. https://www.admiddleeast.com/sharjahs-al-bait-hoteloffers-the-experience-of-an-old-village-retreat. Accessed on: 24 Feb. 2020. 